\title{
Design \& development of bidirectional solar tracking system implemented in western region of Maharashtra
}

\author{
Jyoti Patole $^{1}$, Aditi Apte ${ }^{2}$ Shweta Suryawanshi ${ }^{3}$ \\ ${ }^{1}$ Jyoti Patole_assistant professor,Annasaheb Dange college of engineering \& technology, Ashta,India \\ ${ }^{2}$ Aditi Apte_assistant professor,Annasaheb Dange college of engineering \& technology, Ashta,India \\ ${ }^{3}$ Shweta Suryawanshi_assistant professor,Annasaheb Dange college of engineering \& technology, Ashta,India
}

\begin{abstract}
Solar energy systems have emerged as a viable source of renewable energy over the past two or three decades, and are now widely used for a variety of industrial and domestic applications. Such systems are based on a solar collector, designed to collect the sun's energy and to convert it into either electrical power or thermal energy. This paper presents the design \& development of bi-directional solar tracking system. Solar tracking allows more energy to be produced because the solar array is able to remain aligned to the sun. The constructed device was implemented by integrating it with $900 \mathrm{~V}$ inverter and 12 volts, $100 \mathrm{AH}$ battery. Due to the atmosphere the sun energy is not as great in the morning and evening compared to noontime, which initiated the development of solar tracker.
\end{abstract}

Keywords:- panel, ARM processor,sensors

\section{INTRODUCTION}

At present, there is a great interest towards solving the energy problems facing the world, more especially the third world countries. This has led to research on alternative energy source that would complement the conventional fossil fuel. The alternatives energy sources include; solar, nuclear and wind, but in this research work we focused on solar energy. Solar energy is the energy generated by harnessing the power of the solar radiation. It is the cleanest source of energy whose use can contribute to saving exhaustible energy sources. Photovoltaic panels convert the sun's radiation to electricity.

Maximizing power output from a solar system is desirable to increase efficiency. In order to maximize power output from the solar panels, one needs to keep the panels aligned with the sun. As such, a means of tracking the sun is required. This is a far more cost effective solution than purchasing additional solar panels. It has been estimated that the yield from solar panels can be increased by 30 to 60 percent by utilizing a tracking system instead of a stationary array

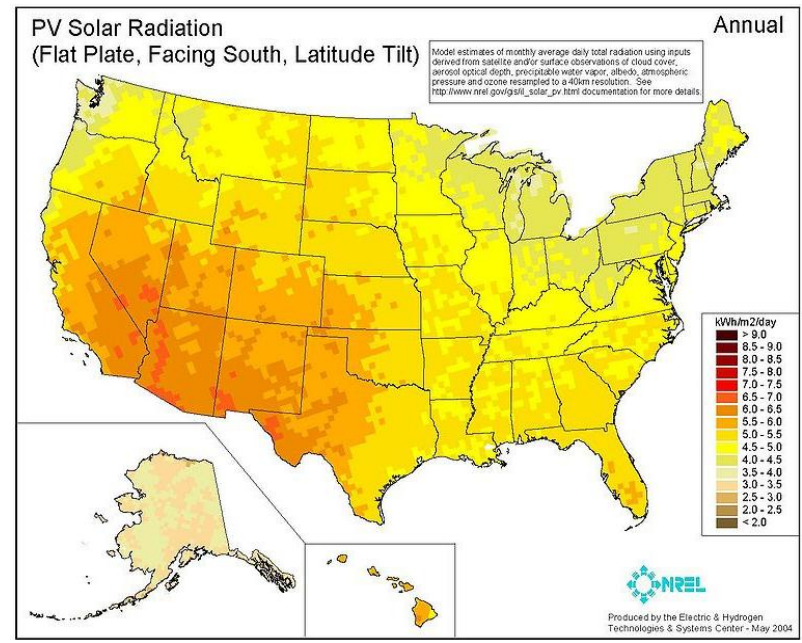

Fig 1.Solar radiations gained by different regions

\subsection{LITERATURE REVIEW}

Photovoltaic power was first discovered by a French scientist Antoinc Becquerel in 1839. The first working solar cell was successfully made by Charles frits in 1882. It was made of thin sheets of selenium and coated with gold. The use of solar panels for generating electricity and heat seems relatively like new development, it has actually been widely used to generate power since early 1900"s. In 1954 bell laboratory 
mass produced the first crystal silicon solar cell. The bell PV cell converted 4\% of the sun "s energy into electricity a rate that was considered the cutting edge in energy technology. Scientists continued to reinvent and enhanced on the design of the original silicon cell and were able to produce a solar cell that was capable of putting $20 \%$ return electricity rate.In the late $1900^{\text {" }}$ s as awareness grew in the science community about the effects of global warming and the need for renewable energy sources, scientists continued to refine the silicon PV and by early 2000 they were able to make a solar cell with $24 \%$ electricity return. In just seven years scientists were again able to increase the electricity return of silicon solar cell using space age materials. By 2007 , modern silicon PV solar cells were operating with $28 \%$ electricity return. Each photovoltaic cell produces a small amount of electricity so they are wired together into panels to provide enough current (D C) power so it must be converted to alternating current $(\mathrm{AC})$ with the aid of an inverter.

\subsection{SOLAR SYSTEM TRACKER}

A solar tracker is an electro-mechanical system used on behalf of orienting a solar photovoltaic panel in the direction of the sun. It is used in many applications such as the transportation signaling, lighthouses, emergency phones installed in the highways, etc... Its main objective is to find the maximum sun radiations in order to get maximum charge for the batteries. A solar tracker is an electro-mechanical device for orienting a solar photovoltaic panel toward the sun trackers, especially in solar cell applications require a high degree of accuracy to ensure that the concentrated sunlight is directed precisely to the powered device.

Solar trackers can be active or passive and may be single axis or dual axis. Single axis trackers normally use a polar mount for maximum solar efficiency and employ manual elevation (axis tilt) adjustment on a second axis, which can be adjusted regularly during the year. Trackers can be relatively inexpensive for photovoltaics. This makes them especially effective for photovoltaic systems using high-efficiency panels. Solar trackers usually need inspection and lubrication on a regular basis. Active trackers, which use motors and gear trains, are controlled by an electronic circuit responding to the solar direction.

\subsection{DESIGN OF THE PROPOSED SOLAR TRACKING SYSTEM}

The proposed solar tracking system should satisfy certain technical requirements specific to the studied application, as follows:

- minimum energy consumption, for the maximization of global efficiency of

the installation and optimum performance-cost ratio;

- reliability in operation, under different perturbation conditions (wind, dust, rain, important temperature variations);

- simplicity of movement solution (motor, gears, sensors), to diminish the

cost and to increase the viability;

- possibility of system integration in a monitoring and control centralized

structure, which means a digital control solution. Taking into account these implicitly necessary technical requirements, the chosen solution to drive the $\mathrm{PV}$ panel is based on the following components:

- a DC electric motor, voltage mode driven, with current monitoring, without

movement sensors (speed or position);

- a motor control system of intelligent drive type, completely digital, that allows the implementation of the digital control of the motor as well as the implementation in a dedicated motion control language of the PV panel orientation application;

- a measurement system for light intensity applied to the PV panel, representing the sensor that commands the solar panel movement.

The chosen technical solution offers the following important advantages:

- simplicity of power scheme: DC motor and $\mathrm{H}$ bridge converter (4 transistors) for the motor drive;

- use of a compact drive equipment, with a high degree of integration and intelligence, that incorporates in a single module both the power converter and its command system, motion command unit (motion controller), and specific automation elements (of PLC type);

- use of an innovative solution, simple and reliable for the measurement system of light signal intensity. 


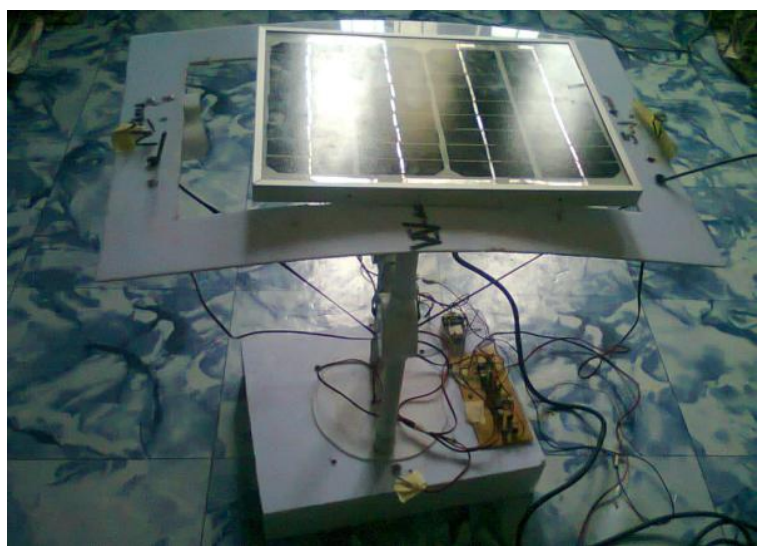

Fig 2: Constructed prototype

\subsection{HARDWARE IMPLEMENTATION}

\subsubsection{Solar Panel}

A photovoltaic module or photovoltaic panel is a packaged interconnected assembly of photovoltaic cells, also known as solar cells. A typical silicon PV cell is composed of a thin wafer consisting of an ultra-thin layer of phosphorus-doped (N-type) silicon on top of a thicker layer of boron-doped (P type) silicon Regardless of size, a typical silicon PV cell produces about $0.5-0.6$ volt DC under open-circuit and no-load conditions. The current (and power) output of a PV cell depends on its efficiency and size (surface area), and is Proportional to the intensity of sunlight striking the surface of the cell. The photovoltaic module, known more commonly as the solar panel, uses light energy (photons) from the sun to generate electricity through the photovoltaic effect. The majority of modules use wafer-based crystalline silicon cells or a thin-film cell based on cadmium telluride or silicon. Crystalline silicon, which is commonly used in the wafer form in photovoltaic (PV) modules, is derived from silicon, a commonly used semi-conductor. The solar panel used in the proposed system is of $4 \mathrm{~W}$ power rating as shown in Fig

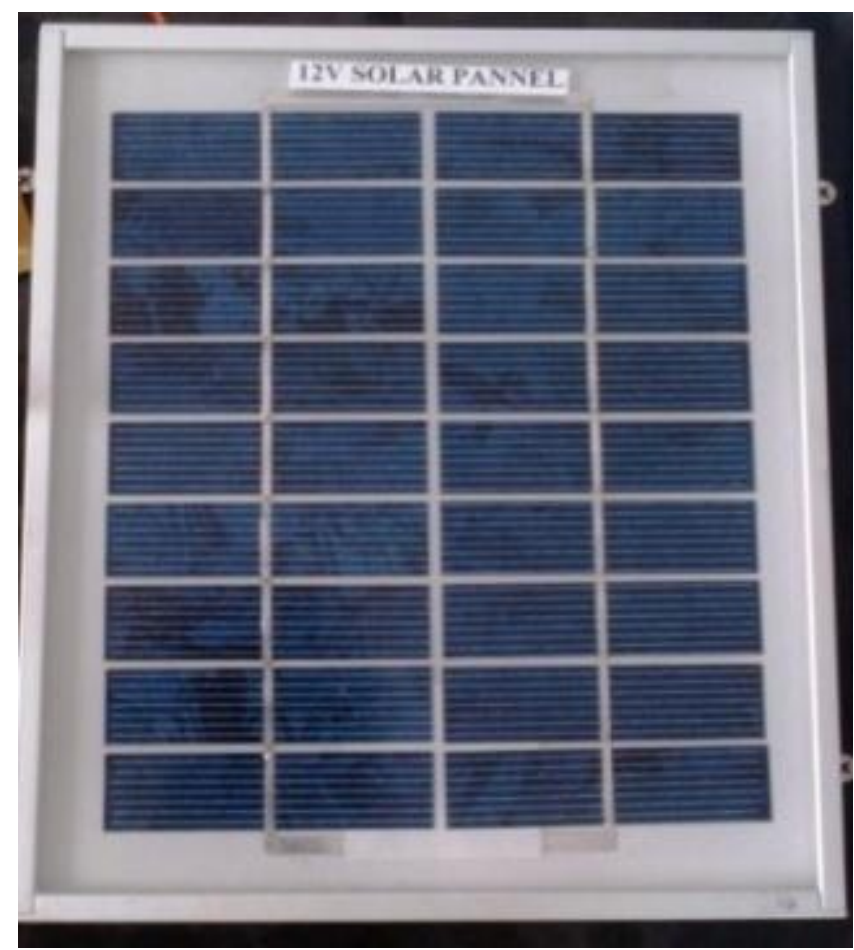

Figure 3:W Solar Panel

\subsubsection{Sensors}

Sensor can be defined as a device which receives a signal and converts it into electrical form which can be further used for electronic devices. The light dependent resistors (LDR) are used in the circuit to sense the change in the sun's position. A photo resistor or light dependent resistor or cadmium sulphide (CdS) cell is a resistor whose resistance decreases with increasing incident light intensity. A photo resistor requires a power 
source because it does not generate Photocurrent a photo effect is manifested in the change in the material's electrical Resistance. Fig. 4 shows a photo resistive cell.

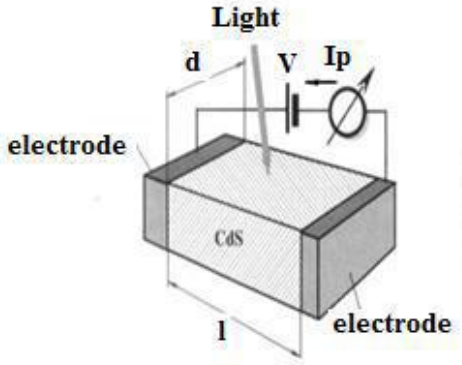

(A)

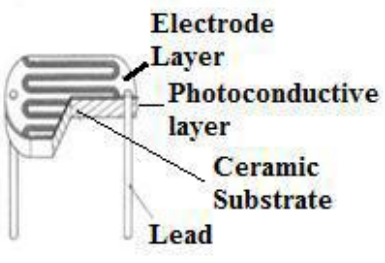

(B)

Figure.4 (A) Structure of a photo resistor and (B) a plastic-coated photo resistor having a serpentine shape

\subsubsection{ARM Processor:}

LPC 2148 is a microcontroller with an internal ARM processor. In this project it gets signals from the light dependent resistors and is used to drive a geared motor to get maximum intensity of light. For this, the microcontroller uses PWMTCR, PWMTC, PWMPR, PWMPC, PWMMR0, PWMMCR, and PWMPCR register to control the direction of the solar panel using pulse width modulation

\section{APPLICATIONS}

In this paper a solar tracker is realized to capture maximum power from sunlight. The position of maximum capture of power is stored in memory. The stored data can be applicable for many applications such as Large photo voltaic panels can track the sun all the day light and by that it give above $65 \%$ efficiency in generating electricity. Solar heaters will also track the sun all the day light and by that less panels are required at the initial cost while in the home automation systems, this system is also needed in turning light ON and Off and also for opening and closing the curtains.

\section{TABLE II. COMPARISON OF THE CURRENT BETWEEN FIXED PV AND USING THE PROPOSED} SYSTEM

\begin{tabular}{|c|c|c|}
\hline Time & $\begin{array}{c}\text { Current using a } \\
\text { fixed PV(mA) }\end{array}$ & $\begin{array}{c}\text { Current using the } \\
\text { Proposed system } \\
(\mathrm{mA})\end{array}$ \\
\hline 08:00 AM & 0.42 & 0.85 \\
\hline 09:00 AM & 0.55 & 0.90 \\
\hline 10:00 AM & 0.75 & 0.92 \\
\hline 11:00 AM & 0.81 & 0.95 \\
\hline 12:00 PM & 0.92 & 0.99 \\
\hline 01:00 PM & 0.95 & 0.99 \\
\hline 02:00 PM & 0.88 & 0.99 \\
\hline 03:00 PM & 0.76 & 0.98 \\
\hline 04:00 PM & 0.42 & 0.95 \\
\hline 05:00 PM & 0.23 & 0.95 \\
\hline 06:00 PM & 0.08 & 0.72 \\
\hline Total & 6.84 & 10.39 \\
\hline
\end{tabular}

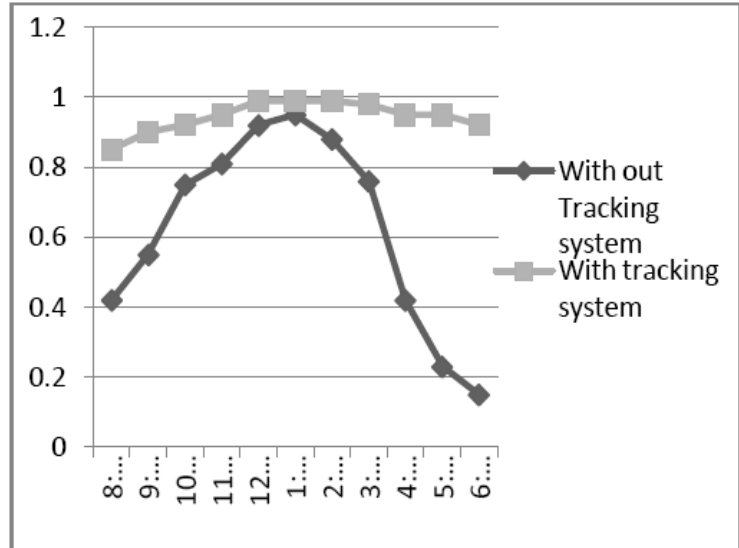

Figure. Efficiency of the Solar Tracking system 
The Fig.9 shows the efficiency of the tracking system. It seems that the efficiency of the proposed system can be increased around $64 \%$ on a summer sunny day. In addition, the proposed system consumes little power to turn the PV panel using a stepper motor instead of using large panel which consumes high power. Moreover, this system can power itself from the PV panel using a $12 \mathrm{~V}$ battery

\section{CONCLUSION}

Maximum current can be obtained from solar panel. Solar trackers are devices used to orient photovoltaic panels, reflectors, lenses or other optical devices towards the sun. Since the sun's position in the sky changes with the seasons and the time of day, trackers are used to align the collection system to maximize energy production. Test showed that power used by tracker system is less than the power gain by tracking the sun accurately. The most important conclusion of this research, is the total cost of construction of the tracker system is very low. This means the system can be mass produced at lower cost and at affordable rate by many communities in the developing countries.

\section{REFERENCES}

[1] Okpeki U.K. otuagoma.S.O "Design and Construction of a Bi-Directional Solar Tracking System" Research Inventy: International Journal Of Engineering And Science Issn: 2278-4721, Vol. 2, Issue 5 (February 2013), Pp 32-38

[2] K. Sreenivasa Rao1, M. Mahesh, “ARM Based Solar Tracking System” International Journal of Modern Engineering Research (IJMER), Vol.2, Issue.4, July-Aug. 2012 pp-2504-2507 ISSN: 2249-6645

[3] Tiberiu Tudorache, Liviu Kreindler "Design of a Solar Tracker System for PV Power Plants" Vol. 7, No. 1,2010

[4] J. A. Beltran, J. L. S. Gonzalez Rubio, C.D. Garcia-Beltran: Design,Manufacturing and Performance Test of a Solar Tracker Made by an Embedded Control, CERMA 2007, Mexico

[5] O. Stalter, B. Burger, S. Bacha, D. Roye: Integrated Solar Tracker Positioning Unit in Distributed GridFeeding Inverters for CPV Power Plants, ICIT 2009, Australia

[6] Zahedi, "Energy, People, Environment, Development of an integrated renewable energy and energy storage system, an uninterruptible power supply for people and for better environment," The International Conference on Systems, Man, and Cybernetics, 1994. 'Humans, Information and Technology', Vol. 3 pp. 2692-2695, 1994.

[7] R. Singh, and Y.R. Sood, "Transmission tariff for restructured Indian power sector with special consideration to promotion of renewable energy sources", The IEEE Conference TENCON-2009, pp. 17, 2009 .

[8] Bailis, Robert. "Wood in Household Energy Use".Encyclopedia of Energy.2004. Pages 516, \& 518.

[9] Ackermann, T., Andersson, G., Söder, L. "Distributed generation: a definition". Electric Power Systems Research. April 2000. Page 195. 